\title{
Assessing the impact of dietary restraint on the accuracy of self-report height and weight for determination of body weight status
}

\author{
K. Hamill ${ }^{1}$, L. Porter ${ }^{1}$, M. Oconnell ${ }^{1}$, A. Moorhead ${ }^{2}$ and A. M Gallagher ${ }^{1}$ \\ ${ }^{1}$ Northern Ireland Centre for Food and Health, University of Ulster, Coleraine BT52 1SA, UK and ${ }^{2}$ School of \\ Communication, University of Ulster, Jordanstown BT37 OQB, UK
}

Body Mass Index (BMI, $\left.\mathrm{kg} / \mathrm{m}^{2}\right)$ is commonly used to define body weight status in population groups ${ }^{(1)}$. In questionnaire surveys self-report height and weight is often used to calculate BMI. However, the extent of accuracy of self-report height and weight is not clear. The aim of this study was to determine the accuracy of self-report height and weight in a group of adults (aged 18-65 yr).

Following consent, a total of 201 participants (mean age 26 (SD 10.24) yr; 105 males, 92 females) were recruited to the study. Following completion of a short questionnaire which included collection of self-report (self-report) height and weight and assessed dietary restraint (using the Dutch Eating Behaviour Questionnaire $(\mathrm{DEBQ})^{(2)}$ height (to the nearest $0.1 \mathrm{~kg}$ ) and weight (to the nearest $0.01 \mathrm{~cm}$ ) of participants was measured (actual). Accuracy of self-report measures was determined (i.e. self-report - actual). Measurements were considered accurate if weight was within $0.05 \mathrm{~kg}$ and height was within $0.05 \mathrm{~m}$.

\begin{tabular}{|c|c|c|c|c|c|}
\hline & Gender & Self-report & Actual & Misreported* & $\mathrm{P}+$ \\
\hline \multirow[t]{2}{*}{ Weight (kg) } & Male $n=105$ & $81.2(12.9)$ & 84.4 (16.3) & $-3.2(6.2)$ & $\overline{0.04}$ \\
\hline & Female $n=92$ & $65.7(11.5)$ & 67.4 (12.9) & $-1.7(3.9)$ & \\
\hline \multirow[t]{2}{*}{ Height (m) } & Male $n=105$ & $1.8(0.1)$ & $1.8(0.1)$ & $0.02(0.03)$ & 0.55 \\
\hline & Female $n=92$ & $1.6(0.1)$ & $1.7(0.1)$ & $0.03(0.03)$ & \\
\hline \multirow[t]{2}{*}{ BMI $\left(\mathrm{kg} / \mathrm{m}^{2}\right) \int$} & Male $n=105$ & $25.2(3.3)$ & $25.4(3.8)$ & $-0.3(2.2)$ & 0.15 \\
\hline & Female $n=92$ & $24.4(4.2$ & $24.2(4.4)$ & $0.2(1.8)$ & \\
\hline
\end{tabular}

Values are means (SD) for 105 male and 92 female participants.*Misreported, extent of misreporting was determined by subtracting the self-report data from the actual data.

$\int \mathrm{BMI}\left(\mathrm{kg} / \mathrm{m}^{2}\right)$ was calculated from self-report or actual height and weight data. $+\mathrm{P} 0.05$, independent $t$-test (males $v s$. females)

Misreport being the wrong report only $4 \%$ of the population accurately reported their weight to within $0.05 \mathrm{~kg}, 89 \%$ accurately reported their height to $0.05 \mathrm{~cm}$. In contrast to previous studies ${ }^{(4)}$ males' under-reported weight to a greater extent than females $($ Table, $P=0.04)$. Actual BMI was negatively correlated with misreporting of weight $(r=-0.47, P<0.001)$ and with BMI determined from self-report information $\left(r=-0.36, P<0.001\right.$. Although dietary restraint was higher in females than males $\left(43 \% v s .19 \%\right.$ respectively, $\left.\chi^{2} P<0.001\right)$ this factor was not associated with differences in accuracy of self-report. In conclusion, the present study indicates that, in this relatively young adult population, height was accurately self-reported whereas accuracy of self-report body weight was negatively impacted by increasing BMI. Overall, self-report height and weight was accurate in determining body weight status. It would be interesting to repeat this study in an older population to determine whether changes in height status associated with ageing impact on accuracy of BMI determined via self-report.

1. World Health Organization (1998) Report of a WHO Consultation of Obesity.

2. Van Strien T, Frijters J, Bergers G et al. (1986) International Journal of Eating Disorders. 5, 295-315. 